\title{
SOLAR ELECTRIC AND CHEMICAL PROPULSION FOR A TITAN MISSION**
}

\author{
Mike Cupples and Shaun E. Green ${ }^{\dagger}$ \\ Science Applications Intemational Corporation \\ Huntsville, Alabama 35806 \\ Benjamin B. Donahue ${ }^{\ddagger}$ \\ The Boeing Company \\ Huntsville, Alabama 35806 \\ Victoria L. Coverstone ${ }^{\S}$ \\ University of Illinois at Urbana-Champaign, \\ Urbana, Illinois 61801
}

Systems analyses were performed for a Titan Explorer Mission characterized by Earth-Satum transfer stages using solar electric power generation and propulsion systems for primary interplanetary propulsion, and chemical propulsion for capture at Titan. An examination of a range of system factors was performed to determine their effect on the payload delivery capability to Titan. The effect of varying launch vehicle type, solar array power level, ion thruster number, specific impulse, trip time, and Titan capture stage chemical propellant choice was investigated. The major purpose of the study was to demonstrate the efficacy of applying advanced ion propulsion. system technologies like NASA's Evolutionary Xenon Thruster

**Presented as AIAA-2003-4728 at the AIAA JPC, Huntsville, AL, July 2003.

- Lead Systems Engineer, Engineering \& Technologies Section

† Systems Engineer, Engineering \& Technologies Section

$\neq 3^{\text {rd }}$ Generation Space Technology Task Lead, Boeing Phantom Works

$\S$ Associate Professor, Department of Aerospace Engineering, Associate Fellow AIAA 
(NEXT), coupled with state-of-the-art (SOA) and advanced chemical technologies to a Flagship class mission. This study demonstrated that a NASA Design Reference Mission (DRM) payload of $406 \mathrm{~kg}$ could be successfully delivered to Titan using the baseline advanced ion propulsion system in conjunction with SOA chemical propulsion for Titan capture. In addition, the SEPS/Chemicai system of this study is compared to an allchemical NASA DRM mission. Results showed that the NEXTbased SEPS/Chemical system was able to deliver the required payload to Titan in 5 years less transfer time and on a smaller launch vehicle than the SOA chemical option.

\section{Introduction}

The Titan Explorer Mission has generated significant interest in the space science community and has been analyzed using various propulsion systems'. Previous analyses covered a wide range of propulsion systems, but did not specifcally investigate the application of an advanced ion propulsion systems like NEXT to the Titan Explorer Misson. This study examines propulsion performance for the Titan explorer mission for a NEXT-based Solar Electric Propulsion System (SEPS) stage combined with SOA and advanced chemical propulsion options. The chemical propulsion system (CPS) is integrated into a full-up spacecraft and is used for Titan capture. At Saturn distances the solar flux is too small to provide adequate solar power to the ion thrusters for propulsion, and hence neccessitates an alternative Titan capture propulsion mode. 
This study will in general investigate the sensitivities of SEPS delivered mass and Titan payload to various system and mission parameters. The SEPS delivered mass is defined as the CPS spacecraft and the total science payload (Titan payload). The Titan payload consists of a direct entry Titan lander and science instruments that remain in Titan orbit. The science instruments that remain in orbit at Titan are referred to in this study as the orbiter science instruments. The first part of this study investigates SEPS delivered mass sensitivity to launch vehicle, opportunity year, transfer time, number of operational ion engines, and ion engine maximum Isp. The second part of the analysis examines Titan payload sensitivity to propellant combination, tank technology, and transfer time.

In this study, launches from both Atlas- $V$ and Delta-IV medium class launch vehicles were evaluated. The launch vehicle injects the SEPS interplanetary transfer stage and CPS spacecraft, along with the Titan payload, on a minimum-propellant optimized trajectory to Saturn with eventual capture of the CPS spacecraft into a circular $2000 \mathrm{~km}$ Titan orit. As a typical example, an Atlas-V 431 launch vehicle injected a total mass of about $4333 \mathrm{~kg}$ to an Earth departure specific energy (C3) of $12.3 \mathrm{~km}^{2} / \mathrm{s}^{2}$. After launch vehicle injection, the SEPS stage is used to propel the CPS spacecraft and Titan payload through a trajectory that includes a Venus Gravity Assist (VGA) enroute to Satum. The SEPS stage is separated from the orbiter at approximately 4 astronomical units (AU) after completing its task. A larger gain in velocity could most likely have been realized with an Earth Gravity Assist (EGA) rather than with a VGA, but the VGA was chosen because of concerns of performing an EGA with a spacecaft that includes a Plutonium based Radioisotope Thermal Generator (RTG) power source (two RTGs are 
baselined in this study for the chemical capture stage). Upon arrival in the Saturn vicinity, the CPS based spacecraft releases the the Titan lander (with aeroshell) onto a Titan direct entry trajectory to Titan, and then the main insertion burn of the CPS places the CPS spacecraft into Titan orbit. Total baseline payload mass that must be delivered to Titan, as taken from the NASA's design reference mission ${ }^{2}$, is $406 \mathrm{~kg}$. This payload consists of $42 \mathrm{~kg}$ of instruments (orbiter science instruments mass) on the CPS stage in Titan orbit and a separate $346 \mathrm{~kg}$ direct entry lander.

Several propellant combinations for the CPS were considered; these included SOA Nitrogen-Tetroxide/Hydrazine $\left(\mathrm{NTO} / \mathrm{N}_{2} \mathrm{H}_{4}\right)$, Liquid-Oxygen/Hydrazine $\left(\mathrm{LOX} / \mathrm{N}_{2} \mathrm{H}_{4}\right)$, Fluorine/Hydrazine $\left(\mathrm{F}_{2} / \mathrm{N}_{2} \mathrm{H}_{4}\right)$, and a high Isp Monopropellant ${ }^{3}$ system. $\mathrm{F}_{2}$ was analyzed for its high performance potential, and the advanced monopropellant was analyzed for its potential of global propulsion system simplicity. For the Titan capture stage, two pressure-fed engines of $100 \mathrm{psia}\left(\sim 6.9 \times 10^{5} \mathrm{~N} / \mathrm{m}^{2}\right)$ chamber pressure $(\mathrm{Pc})$ and $100 \mathrm{lbf}$ (445 N) thrust were assumed throughout the analyses. Advanced CPS tank technologies considered in this study included tank liner thickness and composite tank overwrap strength. 


\section{Systems Analysis}

\section{Launch Vehicle Models}

Launch mass versus launch C3 performance data taken from the vendor's literature $^{4,5}$ for the Delta-IV 4450, Atlas-V 421, and Atlas-V 431 launch vehicles were used in performing trajectory optimization. Appropriate curve-fits of the launch vehicle data were used directly in the trajectory optimization code to provide the optimum mass and C3 required to perform the mission based on other system and mission assumptions, including destination and transfer time.

\section{SEPS System Models}

SEP vehicle synthesis models were used to provide estimates of the spacecraft mass. Table 1 shows the baseline power and propulsion system assumptions used for analyses. A graphic of the main SEPS system and subsystem elements modeled is shown in Figure 2. After computing the mass of the electric power system (power generation, conditioning and distribution), propulsion system (power processing units (PPU), thrusters, gimbals, actuators, Digital Control Interface Units (DCIU), and cables/harness), propellant management (fluid management and tank thermal conditioning), and structures (bus, adaptors, mechanisms, thruster support, ppu support, tank support, and other component attachment), the remaining mass allocation represents the usable mass that can be delivered to the destination. The mass referred to herein as the "SEPS delivered mass" is the difference between the launch vehicle interplanetary injection mass and the wet mass of the SEPS stage. Determining the 
SEPS vehicle's wet mass was a primary task of this study and the discussion that immediately follows focuses on the SEPS primary power and propulsion systems.

Table 1. Baseline SEPS stage power and propulsion systems definition

\begin{tabular}{|l|l|}
\hline Power & $\begin{array}{l}30 \mathrm{kWe} \text { at 1 AU end-of-life (EOL) arrays; 25 kWe } \\
\text { maximum into lon Propulsion System (IPS). } \\
\text { Housekeeping power is assumed to be covered by 5 } \\
\text { additional kWe array reserves. }\end{array}$ \\
\hline Array & $\begin{array}{l}\text { Multi-Junction GaAs arrays; AEC Ultra-Flex design; } \\
\text { Arrays feathered at distances < } 1 \mathrm{AU}\end{array}$ \\
\hline Thrusters & $\begin{array}{l}4 \text { thrusters with 1 spare; } ~ 6 \mathrm{kWe} \text { @ } 4000 \mathrm{sec} \text { Isp; high } \\
\text { Isp throttling, NEXT design; Molybdenum grids. }\end{array}$ \\
\hline PPU & $\begin{array}{l}4 \text { PPUs with 1 spare; cross strapping PPUs; } ~ 6.25 \mathrm{kWe} \\
\text { maximum power, NEXT design }\end{array}$ \\
\hline Radiators & SOA heat pipe radiators. \\
\hline DClU & SOA Digital Control Interface Unit \\
\hline Tank and Propellant & Tank fraction=5\% (SOA); supercritical Xe propellant \\
\hline $\begin{array}{l}\text { Propellant } \\
\text { Management }\end{array}$ & NEXT design \\
\hline
\end{tabular}

\section{SEPS Power}

High-efficiency solar photovoltaic arrays provide power for propulsion and vehicle housekeeping (with the exception of battery power that must be provided for array deployment). The array model was based on high-efficiency triple-junction GaAs cells with an Ultra-Flex ${ }^{6}$ structure; the initial power selected was $31.5 \mathrm{kWe}$, representing the $30 \mathrm{kWe}$ baseline plus $5 \%$ margin. A 2 percent per year degradation factor was applied 
to all solar array masses to account for expected radiation degredation during the mission, including increased degradation due to less than one-AU operation of the propulsion system during certain peroids of time prior to and after the Venus gravity assist. The Ultra-Flex model used provides a current SOA in lightweight solar array technology. Low-Intensity Low-Temperature ${ }^{7}$ (LILT) effects were also accounted for in the power generation model.

\section{SEPS Propulsion}

The electric propulsion subsystem models include the following: PPU, thruster, gimbals and gimbal actuators, DCIU, propellant management system, cable \& harness, and support structure. For all cases evaluated, including variations on thruster number, a spare propulsion string consisting of thruster, PPU, and propellant management system is included in the SEPS. The baseline SEPS configuration used an array of 5 NEXT ${ }^{8,9}$ ion thrusters (four active and one spare) operating in the high isp throttling mode. The NEXT-class advanced ion engines operate at a maximum power level of about $6 \mathrm{kWe}$. Two cases of maxiumum Isp were investigated, $3600 \mathrm{sec}$ and $4000 \mathrm{sec}$, to determine the SEPS stage sensitivity to thruster Isp level. The NSTAR ion thruster which has a demonstrated maximum thruster power level of about $2.3 \mathrm{kWe}$ at a maximum Isp of $3120 \mathrm{sec}$. 


\section{Other SEP Systems}

Other SEPS vehicle subsystem models play a critical role in determining the overall mass of the spacecraft, and therefore affect delivered mass to the destination. All subsystems accounted for in the SEPS model are shown in Figure 1.

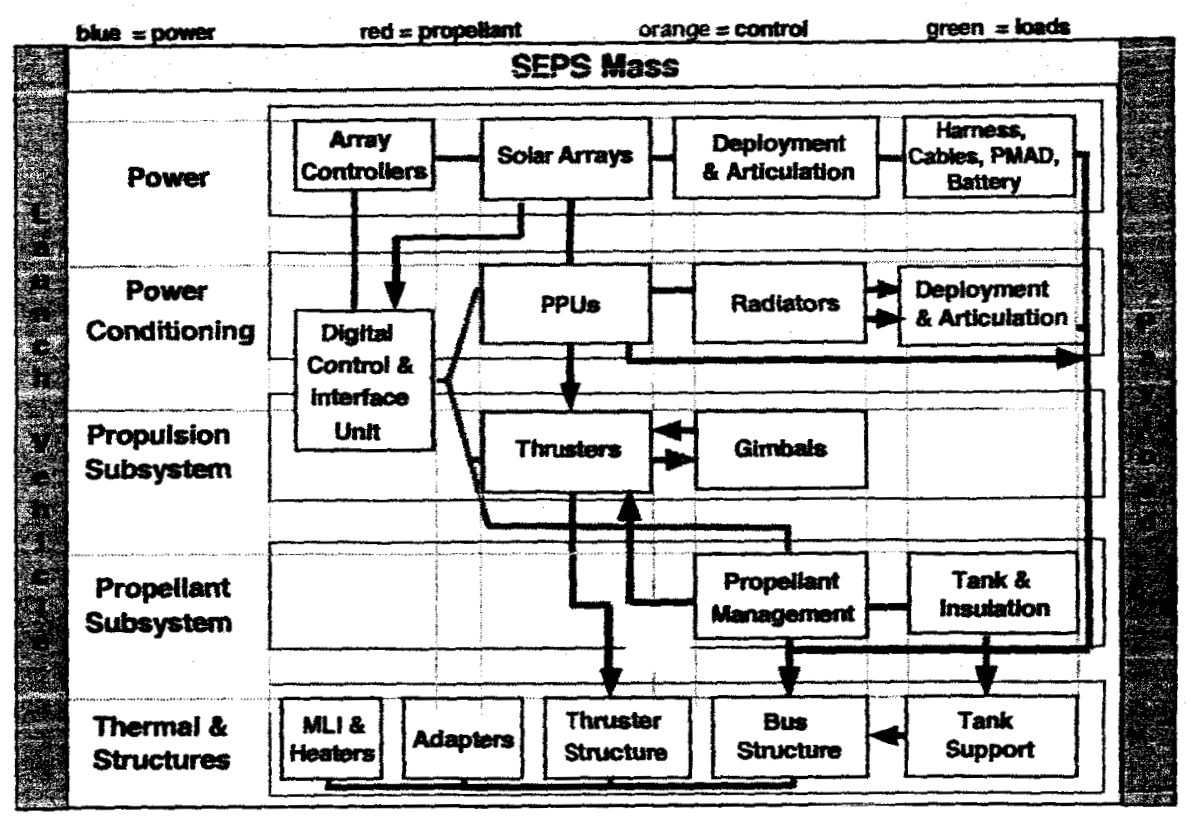

Figure 1. Total SEP System Definition Model Diagram

For each subsystem block indicated in Figure 1, the vehicle synthesis code computes the mass. These masses are then deducted from the total launch vehicle injected mass to obtain the final SEPS delivered mass to Saturn vacinity. SEPS analyses required various assumptions concerning mass and power margins, contingencies, and vehicle system redundancies. These assumptions are shown in Table 2. 
Table 2 SEP System Contingencies, Margins, and Other Assumptions

\begin{tabular}{|l|l|}
\hline Launch Vehicle & $2 \%$ nominal capacity \\
\hline $\begin{array}{l}\text { Xe propellant reserve, residual, } \\
\text { navigation and trajectory } \\
\text { corrections }\end{array}$ & $10 \%$ of deterministic propellant \\
\hline Chemical Capture Stage $\Delta V$ & $\begin{array}{l}2.5 \% \text { G-loss; out-of-tangency Titan } \\
\text { rendezvous } 2 \%\end{array}$ \\
\hline Array end-of-Life contingency & $14 \%$ of baseline power mass \\
\hline SEPS propulsion duty cycle & $95 \%$ of total time SEPS is active \\
\hline Dry Mass & $30 \%$ of non-delivered dry mass \\
\hline SEPS power & $5 \%$ of baseline power dry mass \\
\hline SEPS Redundancy & 1 extra thruster, PPU, gimbal and DCIU \\
\hline Attitude Control System & $\begin{array}{l}\text { Provided by IPS during low thrust operation; } \\
\text { by RCS during ion engine off (scheduled } \\
\text { operations coasts) }\end{array}$ \\
\hline
\end{tabular}

\section{Titan Capture Stage Chemical Propulsion System Models}

Planetary capture CPS models were derived from curve-fits of historical data and physics-based models. For example, the composite overwrap tank model is scaled from the Advanced X-ray Astrophysics Facility ${ }^{11}$ vehicle's composite tank. The baseline CPS consists of two $100 \mathrm{lbf}(\sim 445 \mathrm{~N})$ class main pressure-fed engines. The thrust level was chosen to keep the finite burn gravity losses to a low percent of total characteristic (ideal) $\Delta V$ during the Titan capture bum. Other elements include the thrust vector control system, propellant thermal conditioning and pressurization systems, and the reaction control systems (RCS). The RCS consists of 16 hydrazine monopropellant thrusters that operate at an Isp of 220 sec. Lightweight tanks using internal tank pressures on the order of 230 psia are baselined. Thermal conditioning is provided for 
tanks, lines, valves, and thrusters. The propellant pressurization system assumes 4500

psia $\left(3.1 \times 10^{8} \mathrm{~N} / \mathrm{m}^{2}\right)$ regulated gaseous Helium. Given this relatively high pressure assumption, the pressurant system mass is based on real gas ${ }^{12}$ considerations, including Helium molecule finite size.

\section{Mission Analysis}

\section{Optimization of SEPS Trajectories}

The Solar Electric Propulsion Trajectory Optimization Program ${ }^{13,14}$ (SEPTOP) was used to generate optimal trajectories to Satum for all cases studied. The trajectory optimization process includes, as an optimization constraint, launch vehicle injection mass capability as a function of C3. SEPTOP was used to generate the interplanetary trajectories for a variety of relevant launch dates, trip times, departure C3's, arrival velocities, power levels, thruster combinations and thruster Isp. SEPS stage propellant, change in velocity $(\Delta \mathrm{V})$, thruster operation time, and thruster throttling and sequencing data, among other data, are also generated as outputs of SEPTOP. Specific thruster models are imbedded into the propulsion system modeling routines, and this allowed detailed sensitivity analyses to be easily performed. Constraints, such as the maximum allowed power output from the solar arrays (done through feathering) and the maximum and minimum thruster operational power levels, can be placed on major system elements. 


\section{Earth-Venus-Saturn Trajectories}

Optimal gravity assists for the outer planet mission investigated tend to be in a class of trajectories termed "energy pumping". This term implies that the vehicle expends time in the inner solar system building energy before the VGA occurs. The optimal energy gain occurs as the vehicle is directed by the SEPS stage into a transfer path that takes it into solar distances between approximately $0.7 \mathrm{AU}$ and $2 \mathrm{AU}$. Most of the vehicles heliocentric velocity increase is gained in this high solar flux region. After building orbital energy, the spacecraft performs a VGA to acquire the additional energy needed to reach Saturn within the prescribed transfer time. An example energy pumping trajectory, shown in Figure 2, illustrates a typical 8.5 year trajectory ${ }^{15}$ used in this study.

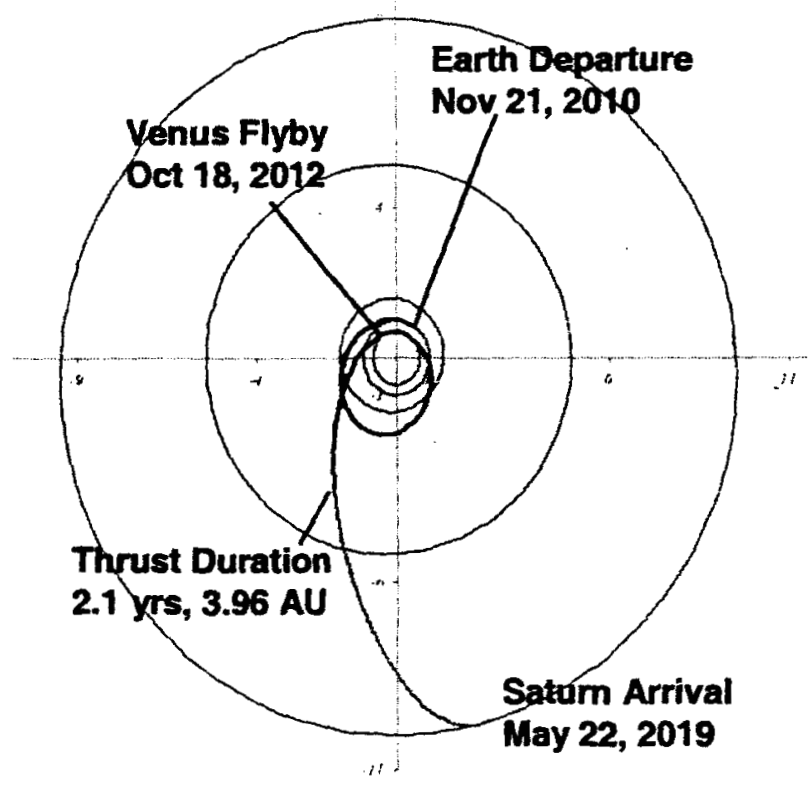


Figure 2. Typical Earth-Venus-Saturn Trajectory

The energy pumping maneuver can be further described in the following sequence of events: 1) the spacecraft increases its potential energy by looping away from the sun, 2) the spacecraft then moves toward the sun (increasing its kinetic energy) achieving VGA (near heliocentric perihelion) and providing a relatively large net heliocentric veiocity increase. For the cases studied, the flyby radius at Venus was constrained to no less that $6352 \mathrm{~km}$, and the typical velocity increase during the VGA ranges from 4.5 to $5.0 \mathrm{~km} / \mathrm{sec}$. Sample SEPS trajectory data showing thruster power-on-time, engine power, and number of engines-on as a function of mission time are shown in Figure 3.

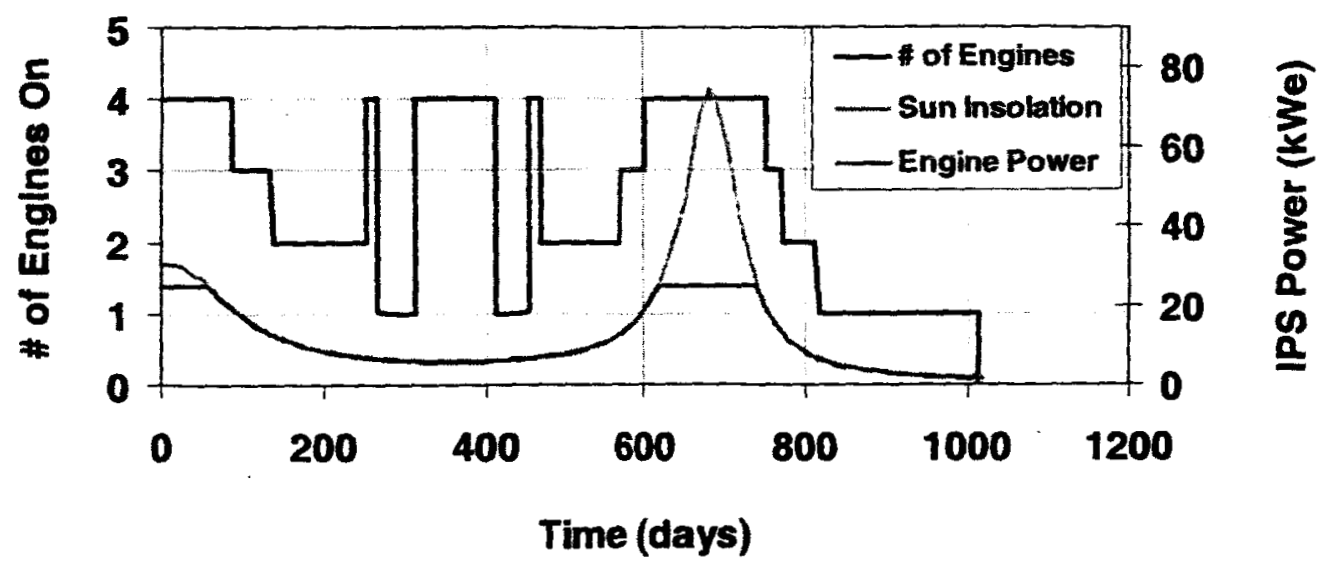

Figure 3. Number of lon Thrusters and Power as a Function of Time

As indicted in the Figure, IPS power is held to a maximum of $25 \mathrm{kWe}$ after SEPS separation from the launch vehicle and array deployment. As the spacecraft moves away from the sun (0-350 days), the number of operational thrusters is reduced as array power decreases, until a single thruster is operating. As the spacecraft returns to a 
lower $\mathrm{AU}$, the number of thrusters increases back to the maximum (four) at 253,300 , and 460 days, as shown in Figures 3 and 4.

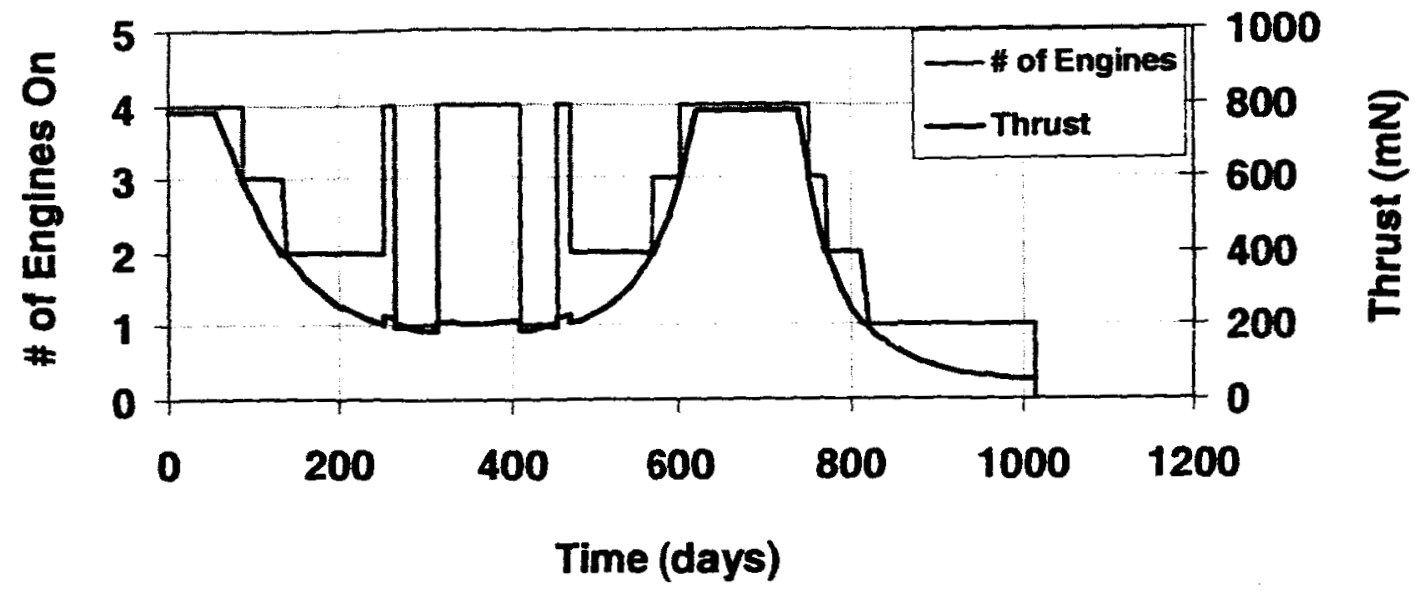

Figure 4. Number of lon Thrusters and Thrust as a Function of Time

For example, the total power into the thrusters at 253 days was $6.8 \mathrm{kWe}$. Although two thrusters would be sufficient to handle this power level, SEPTOP selected four active thrusters, assuring an optimal trajectory based on the global set of power, propulsion, and constraints. Essentially, at this point in the trajectory and at the related power level, higher thrust provided by four thrusters operating at lower power was more important than the higher efficiency operation of two thrusters operating at higher power. The longest duration of four active thrusters occurs from about 600 to 750 days (during this period, the spacecraft will reach its closest distance from the sun) and the VGA occurs at 700 days. For IPS power limiting and array thermal control purposes, solar array feathering is required during low $\mathrm{AU}$ phases of the mission. Figure 3 shows that IPS power is held at $25 \mathrm{kWe}$ during the feathered periods; $0-60$ and $620-740$ days. The SEPS stage is jettisoned, and CPS coasting begins at about 4 AU (1015 days, 2.8 years) as shown in Figures 2,3 and 4. At this time, the CPS with the total Titan payload 
begins an additional 2088 day ( 5.7 years) coast prior to the Titan chemical propulsion capture maneuver. During this coast, power is provided by the RTG system.

A representation of the full Titan Explorer spacecraft concept is shown in Figure 5. The SEPS stage is shown on the bottom of the stack with its dual $15 \mathrm{kWe}$ solar arrays deployed. Five ion thrusters, enclosed on their perimeter by a sun shield, are pictured at the bottom of the craft. On top of the SEPS stage is shown a cut-away view of the CPS spacecraft showing the position of its two main propellant tanks. On the top of the CPS spacecraft, the conical shaped Titan lander module is shown.

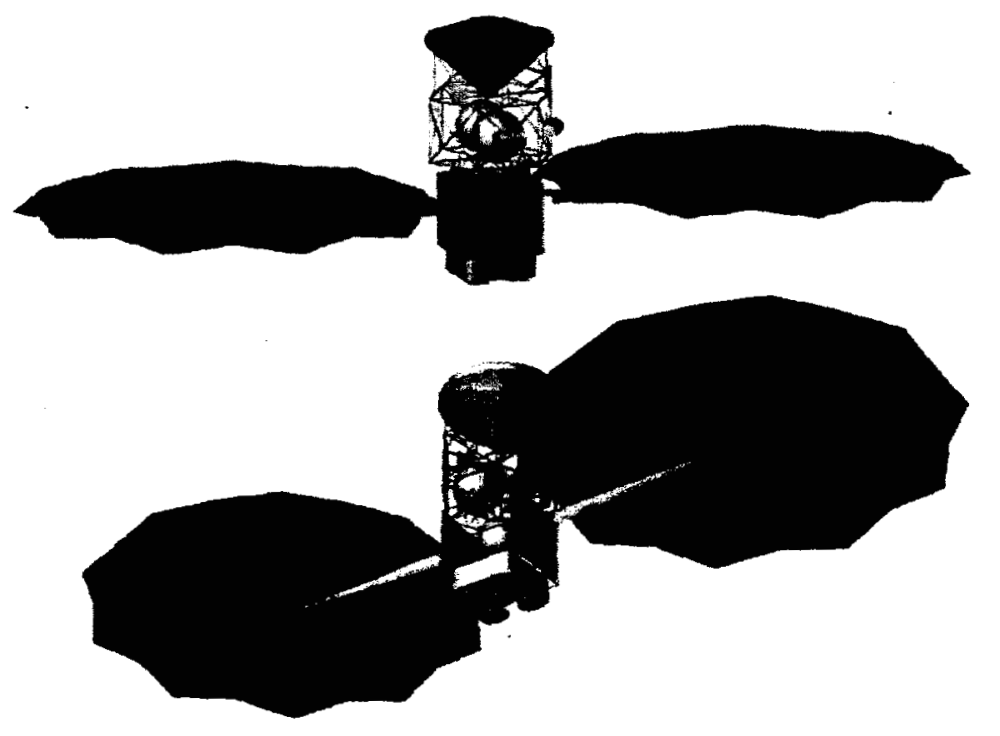

Figure 5. Titan Explorer Mission Propulsion System Concept

\section{Titan Capture Scenario}

Table 3 shows a summary of a typical $\triangle V$ budget for a CPS Titan stage of the type studied. These data are for a system using an Atlas-V 431 launch vehicle, a 30 kWe SEPS stage and the baseline $\mathrm{NTO} / \mathrm{N}_{2} \mathrm{H}_{4}$ CPS. Aimpoint ${ }^{16}$ approach calculations indicated a $3455 \mathrm{~m} / \mathrm{s}$ capture $\Delta \mathrm{V}$. The calculation includes Saturn and Titan orbital 
geometry considerations, Titan approach uncertainty contingency, gravity losses (glosses), and navigation/mid-course $\Delta \mathrm{V}$ correction. An assumed contingency for out-oftangency Titan rendezvous of 2 percent of ideal $\Delta V(66 \mathrm{~m} / \mathrm{sec})$ was included. The capture burn maneuver includes approximately 8 degrees of plane change. In addition to the aforementioned $\triangle \mathrm{V}$ margins, the CPS carries an additional 5.6 percent for propellant reserve, residuals, and margin.

Table 3 Typical Titan Capture $\Delta V$ Budget

\begin{tabular}{|l|r|l|}
\hline Titan Gravitational Parameter & $9.027 \times 10^{3}$ & $\mathrm{~km} / \mathrm{s}^{2}$ \\
\hline Titan Radius & 2575 & $\mathrm{~km}$ \\
\hline Circular Capture Orbit Altitude & 2000 & $\mathrm{~km}$ \\
\hline Excess Velocity (Vhp) Relative to Titan & 4250 & $\mathrm{~m} / \mathrm{sec}$ \\
\hline Hyperbolic Velocity at Titan Periapsis & 4691 & $\mathrm{~m} / \mathrm{sec}$ \\
\hline Circular Velocity at Titan Capture Orbit & 1405 & $\mathrm{~m} / \mathrm{sec}$ \\
\hline Characteristic Capture $\Delta V$ & 3287 & $\mathrm{~m} / \mathrm{sec}$ \\
\hline Contingency: Orbit Insertion Uncertainty & .66 & $\mathrm{~m} / \mathrm{sec}$ \\
\hline Finite Burn Losses (g-losses) & 82 & $\mathrm{~m} / \mathrm{sec}$ \\
\hline Navigation \& Trajectory Correction $\Delta V$ & 20 & $\mathrm{~m} / \mathrm{sec}$ \\
\hline & & \\
\hline Total $\Delta V$ (propulsive capture) & 3455 & $\mathrm{~m} / \mathrm{sec}$ \\
\hline
\end{tabular}

\section{Gravity Loss Analysis for Titan Capture}

The Titan approach was modeled, and an integrated trajectory was generated to estimate the actual finite burn losses ( $g$-losses) at capture. A g-loss calculation example is shown in Figure 6. Calculations were based on a total mass of CPS plus orbiter science instruments and a Titan capture-bum with the two previously mentioned pressure-fed engines. The required bum time to capture was 4210 seconds; the calculated $\Delta V$ loss was $72 \mathrm{~m} / \mathrm{sec}$, or 2.1 percent greater than the ideal $\Delta V$. Therefore, to be conservative, all CPS main propellant requirements assumed g-losses of 2.5 percent of ideal $\Delta V$. 


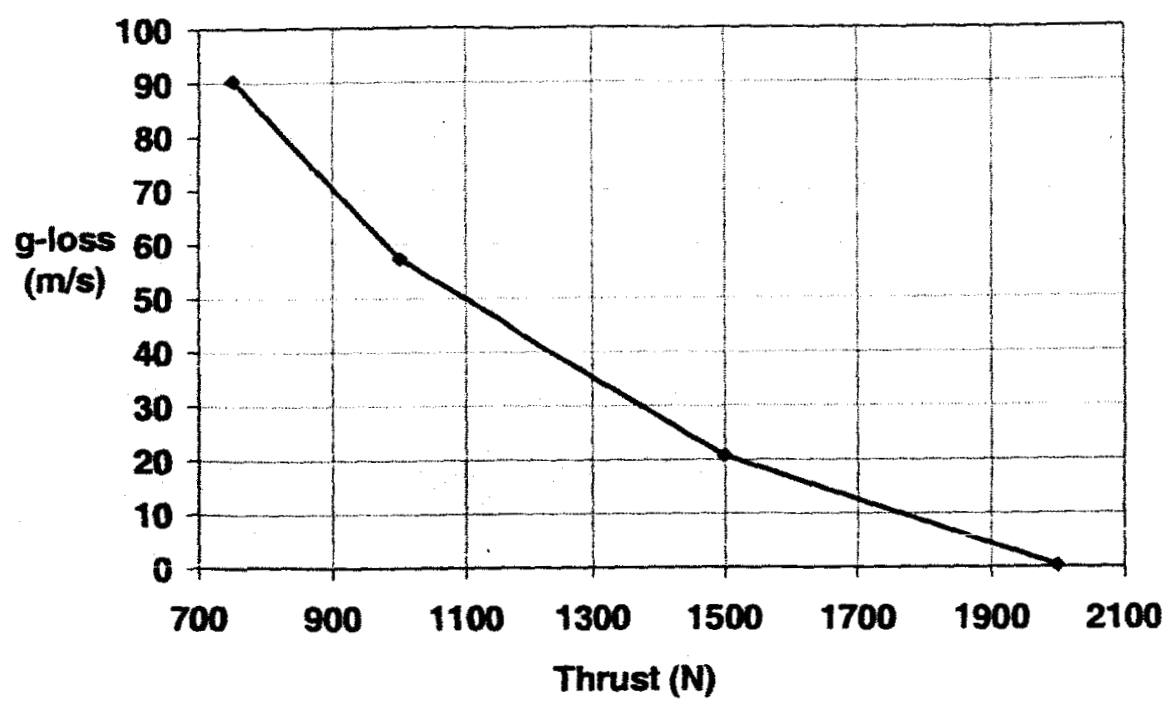

Figure 6. Finite Burn g-Loss at Titan Capture vs Thrust Magnitude

\section{SEPS Mass Delivery Sensitivity Analyses Results}

\section{SEPS Delivered Mass Sensitivity to Launch Date and Launch Vehicle}

A launch opportunity analysis was conducted for Earth departure dates of 2007 through 2025. Figure 7 shows SEPS-delivered mass to Saturn, including the mass of the inert SEPS stage for a number of cases. Both the Atlas-V 421 and 431 and Delta-IV 4450 medium class launch vehicles generally provide greater than $2400 \mathrm{~kg}$ of usable mass over transfer times from 6 to 9 years and for the most favorable launch opportunities 2007, 2010 and 2015. SEPS delivered mass capability generally decreases as Earth-departure year increases over the range examined. The percent difference in the delivered mass over this range is about 8 percent. The 2007 mission provided the largest delivered mass, $2540 \mathrm{~kg}$, and the 2010 opportunity provided the next largest mass, $2500 \mathrm{~kg}$ (both at appproximately 8-year trip times). 


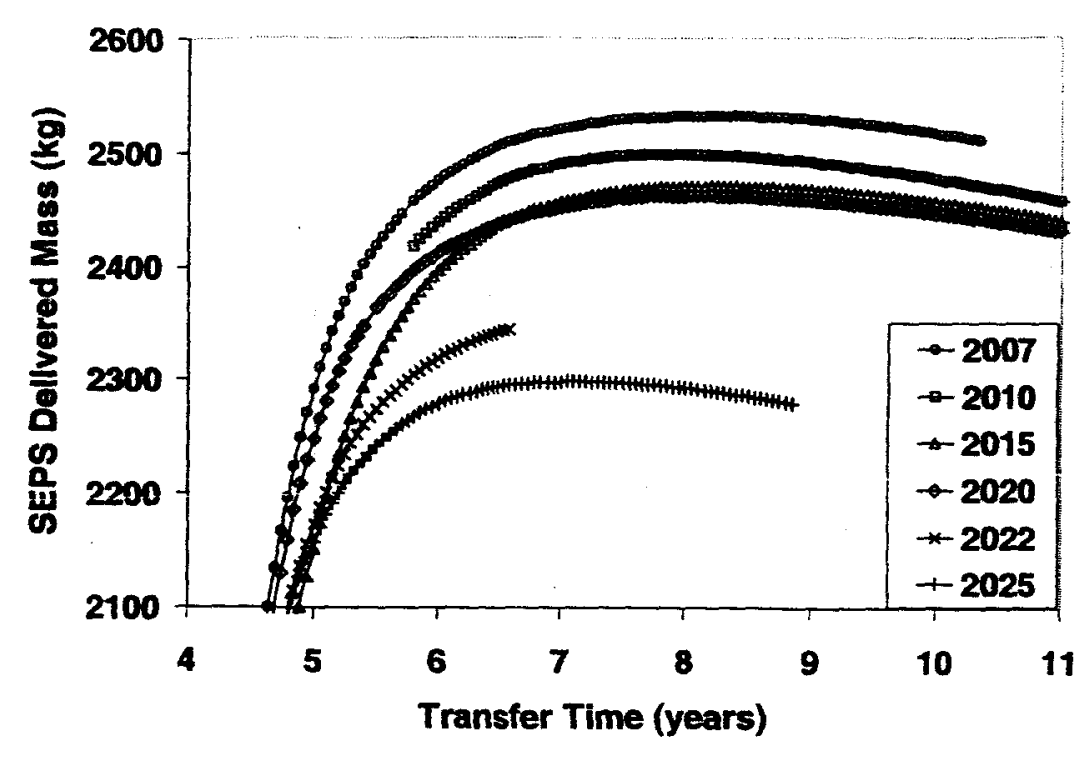

Figure 7. Launch Opportunity Comparison

All results shown hereafter will be from the 2010 launch case which is considered a representative opportunity. For this 2010 opportunity, an analysis was conducted to determine the sensitivity of SEPS delivered mass for three launch vehicle selections. The resulting SEPS delivered masses are shown in Figure 8. As shown in the Figure, the percent delivered mass increase between the Delta-IV 4450 and Atlas-V 421 vehicles was approximately 10 percent; the increase provided by the Atlas-V 431 over the Atlas-V 421 was about 12 percent. 


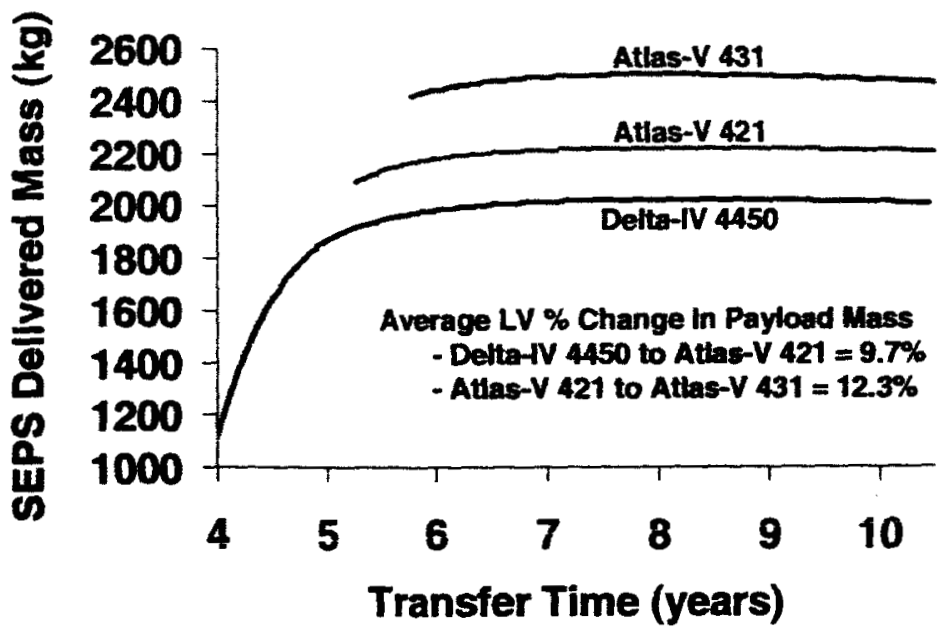

Figure 8. Variation in SEPS Delivered Mass with Launch Vehicle

\section{SEPS Delivered Mass Sensitivity to Electric Propulsion Isp}

A thruster Isp sensitivity study was performed to determine the variation in SEPS delivered mass with Isp. As shown in Figure 9, for the power levels investigated, and using the Atlas-V 431 launch vehicle, only small differences in SEPS delivered mass were found for thruster Isp values of $3600 \mathrm{sec}$ and $4000 \mathrm{sec}$. The $4000 \mathrm{sec}$ thruster was chosen for the remaining analyses in this paper due to this demonstrated thruster insensitivity to Isp, and because greater thruster lifetimes will in general be technically easier to achieve for the higher Isp thruster. 


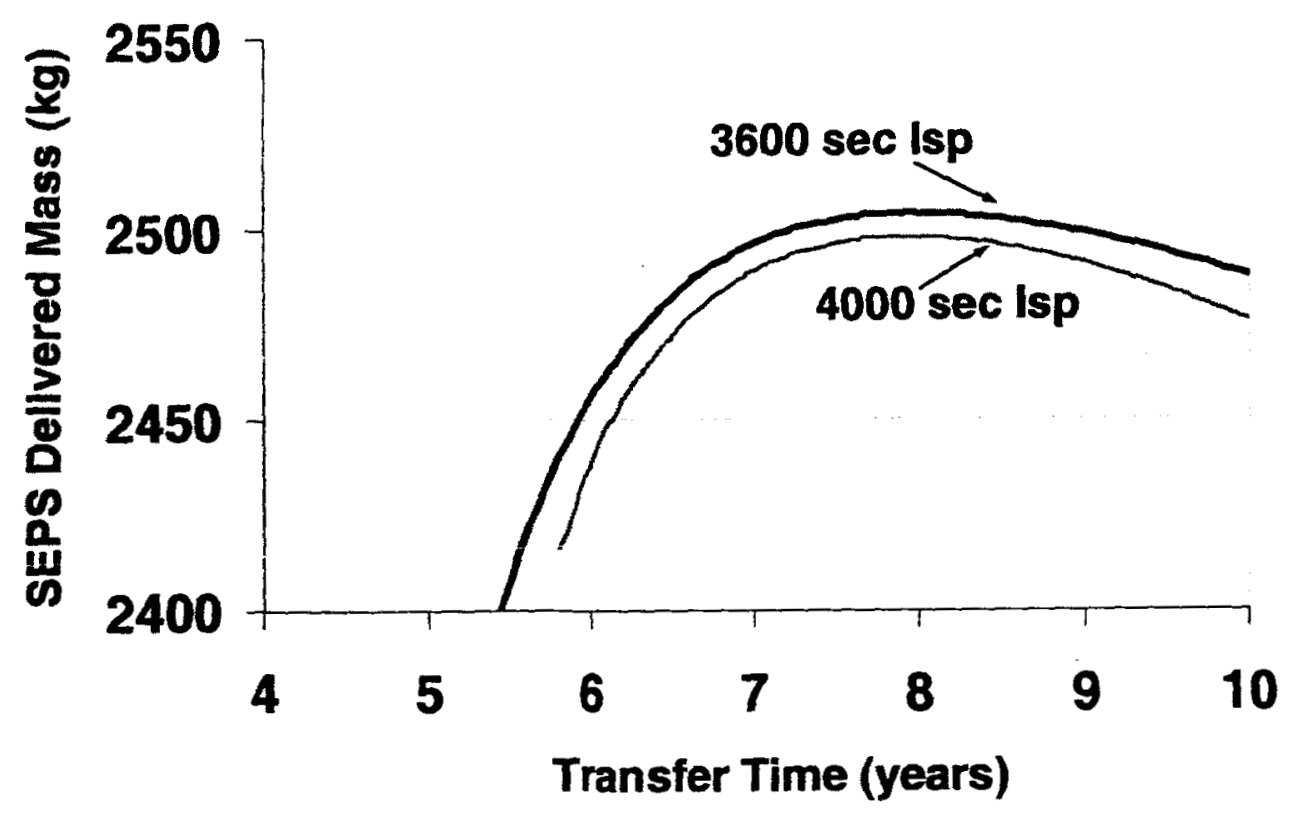

Figure 9. Impact of Thruster Isp on SEPS Delivered Mass

\section{SEPS Delivered Mass Sensitivity to Total Number of Active Thrusters}

Further analyses were performed to determine whether an increase in the number of SEPS thrusters along with associated increase in array power would dramatically increase the SEPS delivered mass to Saturn vicinity. Results, shown in Figure 10, indicated that by increasing the number of operational thrusters from 4 to 5 , the SEPS delivered mass to Satum vicinity increased by about 3 percent. Note however, that in going from 4 to 5 operational thrusters there will likely be a significantly higher cost associated with increased power and one additional thruster, PPU, and propellant management string, while the actual increase in Titan payload will be relatively small.

Figure 10 also indicates the reduction in trip time facilitated by five thrusters for an example SEPS delivered mass of $2500 \mathrm{~kg}$ (note, this example SEPS delivered mass 
represents a conservative estimate of the required mass for the CPS spacecraft and total Titan payload). The approximately 8-year trip time is required to deliver the 2500 $\mathrm{kg}$ to Saturn vicinity for the 4 thruster SEPS can be reduced to about 5.7 -years by the 5 thruster system. Note that both Saturn and Titan arrival Vhp are also shown in Figure 10. In this study, Saturn Vhp defines the relative velocity (sometime called the excess velocity) of the CPS spacecraft in the heliocentric coordinate system with respect the Saturn. Likewise, Titan Vhp defines the relative velocity in Saturn-centered coordinates of the CPS spacecraft with respect to Titan. As can be gleaned from Figure 10, the Vhp at Satum arrival increases dramatically as the transfer time falls below the 7.5-year transfer time. This sharp increase in Saturn Vhp with decrease in transfer time, coupled with a Titan payload that falls off rapidly with increasing Saturn Vhp, implies that the SEPS delivered mass benefit with 5 thrusters is quickly lost with decreasing transfer time. Note that Titan payload sensitivity with Saturn and Titan Vhp will be more thoroughly covered in an upcoming section that addresses Titan payload sensitivities.

For completeness, a three operational thruster SEPS configuration was investigated as well. This configuration was marginally successful in placing the reference payload at Titan. The average thruster throughput for the 3 engine case, however, was significantly higher than the baseline NEXT program design value of 270 kg per thruster. 


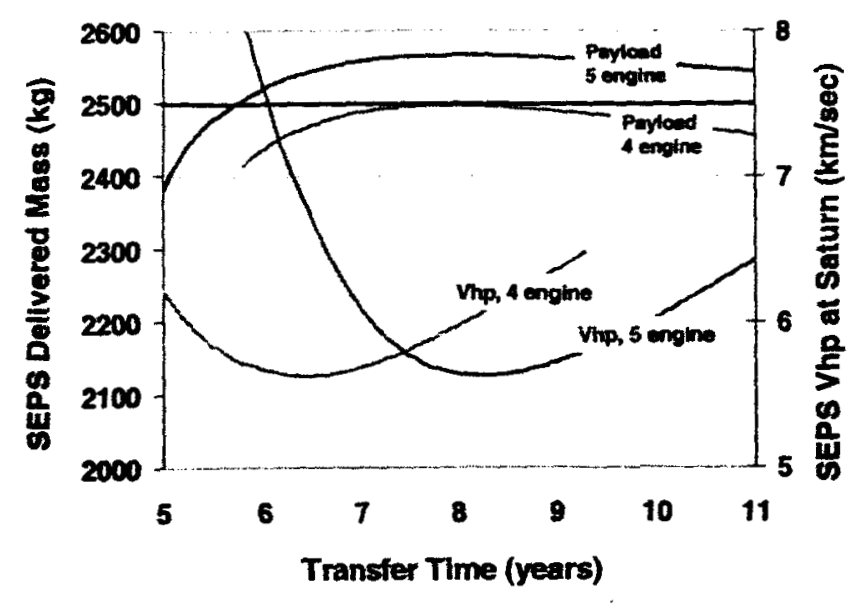

Figure 10. SEPS Delivered Mass Sensitivity to No. of Operational Thrusters

\section{Titan Payload Delivery Sensitivity Analyses Results}

\section{Titan Payload Sensitivity to Launch Vehicle and Transfer Time}

A shift is now made from considering SEPS delivered mass to considering actual Titan payload. Titan payload has been defined as the direct entry lander and the previously mentioned orbiter science instruments. The transfer vehicle is the previously baselined combined 4 thruster SEPS (4000 sec Isp) stage and the $N T O / \mathrm{N}_{2} \mathrm{H}_{4}$ based CPS spacecraft. The SEPS stage provides the primary interplanetary propulsion that sends the CPS with total science payload to the Saturn vicinity. As the CPS spacecraft arrives in Saturn vicinity, the direct entry lander is seprated from the spacecraft and proceeds to Titan for direct entry and landing. Subsequent to lander release, the remaining CPS based spacecraft with the orbiter science instruments proceeds to Titan for a chemical based capture maneuver. The total science payload (Titan payload) delivered to Titan as a function of transfer time, launch vehicle type, and arrival Vhp is illustrated in Figure 11. This figure shows that Titan payload maxima are reached at 
approximately 8.5 years. The NASA reference Titan payload value (Ref. 2) is shown in Figure 11 as a bold, horizontal line. Actual estimated payload delivery capability is shown in Fig. 11 as a series of curves; one curve for each of the three different launch vehicles. The baseline transfer vehicle can deliver the DRM payload to Titan in 7.0 years if launched by an Atlas-V 431, and in 7.5 years if launched by an Atlas-V 421. Titan payload delivered with the Delta-IV 4450 (the smallest launcher considered) in 8.5 years is $390 \mathrm{~kg}$, just under the $406 \mathrm{~kg}$ DRM payload. At 8.5 years, the Atlas-V 431 and 421 vehicles delivered 505 and $437 \mathrm{~kg}$ payloads, respectively. The maximization of Titan payload at 8.5 years can be understood by noticing that the minimum Titan Vhp is reached at 8.5 years. Minimum $V h p$ at Titan translates into minimum propulsive $\Delta V$ for the CPS capture, and thus maximum Titan payload.

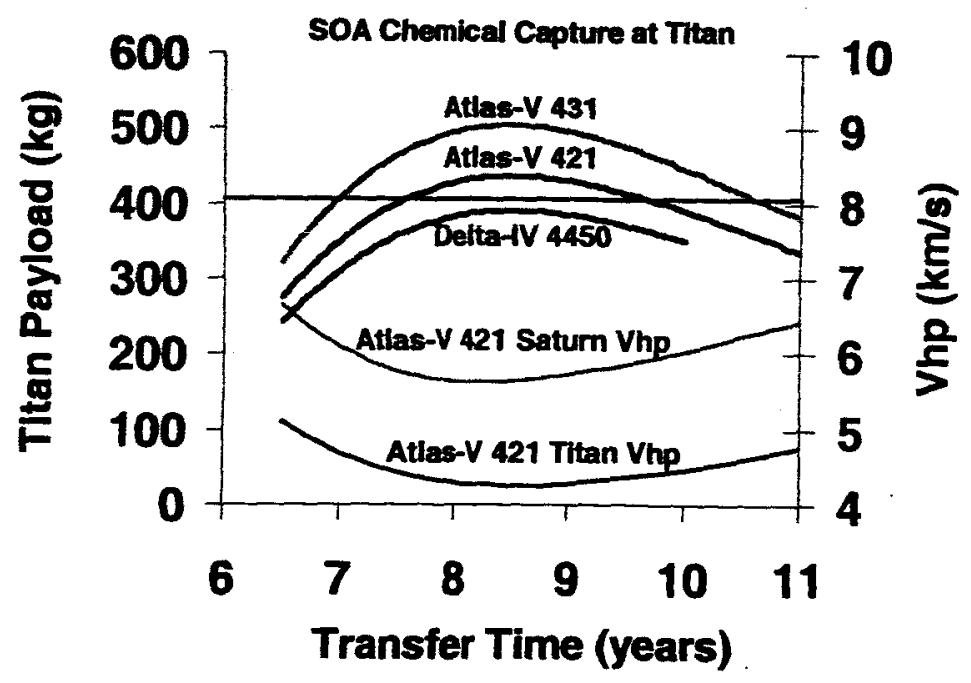

Figure 11. Titan Payload Sensitivity to Transfer Time \& Launch Vehicle 


\section{Orbiter Science Mass Sensitivity to Chemical Propellant Combinations}

A detailed deliniation of subsystem mass is provided in this section to clarify the relationship that orbiter science instruments mass has to chemical propellant combination. Three potential CPS systems were considered, and Table 4 shows the corresponding SEPS stage and CPS spacecraft mass data for the three chemical propellant combinations. For this study, the baseline assumptions include Atlas-V 431 launch vehcile, a 8.5 year trip time, and the baseline 4 SEPS configuration. The SOA NTO/ $\mathrm{N}_{2} \mathrm{H}_{4}$ case has been previously described in Figure 11. For each of the propellant combinations shown in Table 4, the SEPS stages are identical, with the dry mass of 848 $\mathrm{kg}$ and a total propellant load of $898 \mathrm{~kg}$. The total SEPS stage mass is $1839 \mathrm{~kg}$. For a total solar array power level of $30 \mathrm{kWe}$ EOL, the SEPS stage specific mass is nearly 61 $\mathrm{kg} / \mathrm{kWe}$.

The total $\Delta V$ for the Titan capture (including all losses) was estimated at 3455 $\mathrm{m} / \mathrm{s}$, and the chemical stage Isp's used in this analysis were $330 \mathrm{sec}, 351 \mathrm{sec}$, and 380 sec for the SOA chemical, the LOX/ $\mathrm{N}_{2} \mathrm{H}_{4}$ system, and the $\mathrm{F} 2 / \mathrm{N}_{2} \mathrm{H}_{4}$ system respectively. The corrosponding dry mass for the chemical systems are $496 \mathrm{~kg}, 533 \mathrm{~kg}$, and $515 \mathrm{~kg}$ respectively. The SOA CPS has the lowest dry mass due to the compact nature of the baseline earth-storable propellant system. The space-storable propellant combinations, $L O X / N_{2} H_{4}$, and $F 2 / N_{2} H_{4}$, required greater dry mass systems due in part to increased subsystem masses for the cryo-coolers and added power to operate the cryo-cooler. Both of the space-storable systems provide orbiter science instruments delivery advantage over the SOA CPS. The orbiter science instruments increase was $12 \mathrm{~kg}$ for 
LOX/N $\mathrm{N}_{2} \mathrm{H}_{4}$ and $99 \mathrm{~kg}$ for $\mathrm{F} 2 / \mathrm{N}_{2} \mathrm{H}_{4}$. These orbiter paylaod increases over SOA chemical can be attributed to the larger Isp that the space-storable propulsion systems provide.

The relatively small $12 \mathrm{~kg}$ orbiter science instruments mass increase over SOA for the LOX/N $\mathrm{N}_{4} \mathrm{H}_{4}$ is considered a marginal increase in total payload delivery capability. A relatively high Titan payload of approximately $600 \mathrm{~kg}$ can be achieved with the $F_{2}$ propellant $^{17,18}$ on an Atlas-V 431 launch. This turns out to be almost $100 \mathrm{~kg}$ more orbiter science instruments mass than the SOA chemical system can deliverer to Titan orbit. In addition, further analyses for $F_{2}$ propulsion showed that the Atlas-V 421 and the Delta-IV 4450 deliver $520 \mathrm{~kg}$ and $460 \mathrm{~kg}$ Titan payload repectively. Thus, with $\mathrm{F}_{2}$ propulsion, the DRM payload can be successfully delivered to Titan for the smallest launch vehicle case investigated. $F_{2}$ engines were tested successfully by NASA and the Air Force during engine development programs of the 1960's and 1970's, however, work on $F_{2}$ has not been done in the last decade. Thus, an appreciable technology development program would be necessary to raise $F_{2}$ propulsion technology to an appropriate Technology Readiness Level prior to in-space application.

Table 4 Total Mass Statement for Chemical Propellant Combinations

\begin{tabular}{|c|c|c|c|}
\hline \multicolumn{4}{|c|}{ All cases are for an 8.5 year transfer time and an Atlas-V 431 launch vehicle } \\
\hline Capture Stage Bi-propellant & $\mathrm{NTON}_{2} \mathrm{H}_{4}$ & $\mathrm{O}_{2} \mathrm{~N}_{2} \mathrm{H}_{4}$ & $\mathrm{~F}_{2} / \mathrm{N}_{2} \mathrm{H}_{4}$ \\
\hline Isp & $330 \mathrm{sec}$ & $351 \mathrm{sec}$ & $380 \mathrm{sec}$ \\
\hline Units & (kg) & $(\mathrm{kg})$ & $(\mathrm{kg})$ \\
\hline Launch Vehicle Adapter & 54 & 54 & 54 \\
\hline \multicolumn{4}{|l|}{ SEPS transfer stage $(\Delta V=8018 \mathrm{~m} / \mathrm{s})$} \\
\hline Xe Propellant Mass & 821 & 821 & 821 \\
\hline Xe Prop Reserves, Residuals & 82 & 82 & 82 \\
\hline RCS propellant, $\mathrm{N}_{2} \mathrm{H}_{4}$ & 5 & 5 & 5 \\
\hline Dry Mass & 848 & 848 & 848 \\
\hline Orbiter Adapter & 29 & 29 & 29 \\
\hline \multicolumn{4}{|l|}{ CPS capture stage $(\Delta V=3455 \mathrm{~m} / \mathrm{s})$} \\
\hline Main Propellant Mass & 1331 & 1286 & 1224 \\
\hline Main Propellant Reserves, Residuals & 149 & 145 & 138 \\
\hline
\end{tabular}




\begin{tabular}{|c|c|c|c|}
\hline RCS propellant, $\mathbf{N}_{\mathbf{2}} \mathbf{H}_{\mathbf{4}}$ & 13 & 13 & 13 \\
\hline Dry Mass & 496 & 533 & 515 \\
\hline Orbiter Science Instruments Mass & 141 & 153 & 240 \\
\hline Lander (Titan direct entry, not captured) & 364 & 364 & 364 \\
\hline Total Initial Mass (Launch $\mathbf{C 3}=12.3$ ) $\left.\mathbf{~ k m}^{2} / \mathbf{s}^{2}\right)$ & 4333 & 4333 & 4333 \\
\hline
\end{tabular}

In addition to the above mentioned propellant combinations, this study investigated advanced monopropellants to determine the efficacy of an advanced monopropellant propulsion system application for this mission class. Analysis indicated that a monopropellant CPS capture stage operating at 275 sec Isp combined with the baseline SEPS stage could not achieve the $406 \mathrm{~kg}$ reference payload for any of the three launch vehicles investigated. The analysis further showed that an Isp of 320 with an Atlas-V 431 launch vehicle would be required for a monopropellant system to deliver the DRM Titan payload.

\section{Orbiter Science Mass Sensitivity to Tank Technology Improvements}

A study was performed to determine the potential Titan payload increase that could be realized from CPS main propellant tank technology improvements. Analyses were performed to determine Titan payload sensitivity to propellant tank liner thickness and composite overwrap thickness. A modest increase in Titan payload of about $15 \mathrm{~kg}$ was found by decreasing tank liner thickness from 30 mil to 5 mil. Recent manufacturing improvements in tank liner technology have achieved this 6 fold decrease in liner thickness. Reducing composite tank overwrap weight was also evaluated. An increase in tank composite overwrap strength by 30 percent resulted in an increase of approximately 3 percent in Titan orbiter science instruments mass. Tank overwrap 
strength technology improvements of 30 percent over SOA are within reach of current tank manufacturing processes.

\section{SEPS/Chemical Transfer System Comparison to an All-Propulsive NASA DRM}

Mission analyses results from an earlier and separate NASA in-house Titan allchemical reference mission is included in this section for comparison purposes. Figure 13 shows three columns of data; the first column on the left of the Figure shows total stack mass data for the baseline SEPS/Chemical system, the middle column shows the total stack mass data for the $F_{2}$ based SEPS/Chemical system, and the column on the right shows the total stack mass for the NASA all-chemical DRM. In this NASA DRM, no SEPS stage was used, and a Delta-IV Heavy launch vehicle was required to inject the

DRM payload (406 kg) into a 12-year Venus-Earth-Earth Gravity Assist (VEEGA) transfer trajectory. Aside from several midcourse correction burns, the all-propulsive Titan CPS coasts for the duration of the mission, gaining much of the required momentum to reach Saturn via the three gravity assists. Because of the VEEGA trajectory chosen, a relatively high arrivial velocity is encountered at Saturn for this DRM as compared to the SEPS mission analysed herein, with its single VGA and 1000+ day ion thrusting duration; this study's SEPS trajectory provides a more moderate Satum arrival velocity, even though its trip time of 8.5 years is significantly less. The higher Saturn arrival velocity of the VEEGA trajectory results in a significantly higher Titan CPS capture stage propellant load as compared to that needed for the CPS of the SEPSNGA mission baselined in this study. In Figure 12, total stack mass is listed for 
two SEPNGA missions (columns 1 and 2) previously described in Table 4, in addition to the aforementioned all propulsive DRM. The primary difference between columns 1 and 2 is the propellant choice for the capture stage. As compared to the all-chemical DRM, the SEPS configuration enables significantly lower total missions mass for a given payload, allowing for the use of a medium rather than a heavy lift launch vehicle. The stack masses of the two SEP configurations presented here are about 35 percent less than the all-chemical DRM system. Also, the baseline SEPS configuration of this study can deliver modestly higher payload to Titan in a 3.5 year shorter trip time than the allpropulsive DRM.

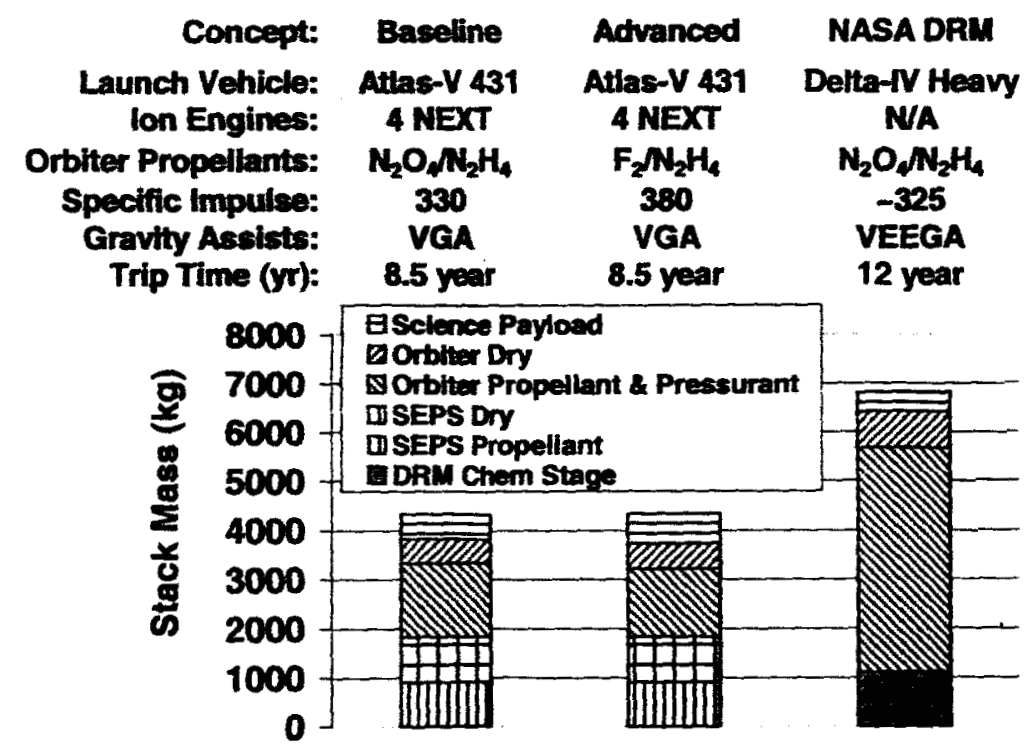

Figure 12. SEPS transfer system total mass compared to the DRM

\section{Conclusions}

This analysis showed that an advanced ion engine based SEPS transfer stage can deliver a NASA DRM payload of $406 \mathrm{~kg}$ to Titan in missions using medium class 
launch vehicles between the years of 2007 to 2015 . These missions can be accomplished with approximately $30 \mathrm{kWe}$ of solar power driving four, $4000 \mathrm{sec}$ Isp, NEXT-class thrusters with single VGA interplanetary transfers and SOA chemical technology for Titan capture. Payloads somewhat greater than the DRM can be delivered at transfer times of approximately 8.5 years using Atlas-V 421 or 431 launch vehicies. Smaller launch vehicles such as the Delta-IV 4450 could not deliver the reference Titan payload using the 4 ion engine/SOA chemical stage combination. For all of the launch vehicle cases investigated, increased Titan payload delivery was shown using a 5 SEPS thruster system, but the improvement was marginal. A three engine case required an ion system capability beyond the design throughput limits of current development programs.

Results of chemical capture stage analyses indicated that the baseline, off-theshelf, storable NTO/N2H4 CPS can do the mission. The advanced Fluorine/ $\mathrm{N}_{2} \mathrm{H}_{4} \mathrm{CPS}$ provided significant (25 percent) Titan payload increase over the baseline $N T O / \mathrm{N}_{2} \mathrm{H}_{4}$ stage, but would require a Fluorine engine technology development program. The LOX $/ \mathrm{N}_{2} \mathrm{H}_{4}$ CPS provided marginal performance improvement over $\mathrm{NTO} / \mathrm{N}_{2} \mathrm{H}_{4}$ and probably does not warrant a new engine development program for this class of engine. Monopropellant based CPS provides no improvements over SOA chemical unless the Isp is greater than 320 sec. Relatively easily obtainable tank technology improvements provide modest Titan payload delivery enhancement capability of the SEPS/Chemical propulsion transportation system. 


\section{Acknowledgements}

This work was performed by SAIC's In-Space Technology Assessment (ISTA) program team under the support and leadership of the In-Space Propulsion Technology Project at NASA MSFC. The efforts of Bill Hartmann, University of llinois Urbana-Champaign, for SEPTOP trajectory generation, are gratefully acknowledged.

\section{References}

1. Noca, M., Frisbee, R., Johnson, L., Kos, L., Gefert, L., and Dudzinski, L., "Evaluating Advanced Propulsion Systems for the Titan Explorer Mission," International Electric Propulsion Conference, Rept. IEPC-01-175, Oct. 2001.

2. Herrmann, M. C., James, B. G., and Lockwood, M. K., "Aerocapture at Titan: Systems Analysis Review, ${ }^{n}$ NASATM-2003-212746, Oct. 2003.

3. Jankovsky, R. S., "HAN-Based Monopropellant Assessment for Spacecraft," AIAA Paper 96-2863, 32nd AIAA/ASME/SAE/ASEE Joint Propulsion Conf., July 1996.

4. "DELTA IV Payload Planners Guide," The Boeing Co., Huntington Beach, CA, Rept. MDC 00H0043, Oct., 2000.

5. "Atlas Launch System Mission Planner's Guide," Lockheed Martin, McLean, VA, Rept. CLSB-0105-0546, rev. 9, Sept. 2001.

6. URL: http://uwww.aec-able.com, Ultraflex Solar Arrays, 2004.

7. Kerslake, T., "Photovoltaic Array Performance During an Earth-to-Jupiter Heliocentric Transfer," NASA Glenn Research Center, Power and Propulsion Office, Rept. IBR PS496, Aug., 2000. 
8. NASA Research Announcement Proposal Information Package, Next Generation Ion Engine Technology, NASA, Nov, 2001, Sec. A.9.2.

9. Patterson, M., Haag, T. W., Foster, J. E., Rawlin, V. K., Roman, R. F., and Soulas, G.

C., "Development Status of a 5/10-kW Class Ion Engine," AIAA Paper 2001-3489, July, 2001.

10. Piñero, L., "Design of a Modular 5-kW Power Processing Unit for the NextGeneration 40-cm Ion Engine," International Electric Propulsion Conference, Rept. IEPC-01-329, Oct. 2001.

11. "Advanced X-ray Astrophysics Facility Mass Properties," NASA Rept. DPD692 SE09, March 1999.

12. Dickerson, R. E., Gray, H. B., Chemical Principles, W. A. Benjamin, Menlo Park, CA, 1970 (1972 corrected printing).

13. Sauer, C., Jr., "Optimization of Multiple Target Electric Propulsion Trajectories," AlAA Paper 73-205, Jan. 1973.

14. Sauer, C., Jr., "Solar Electric Propulsion Performance For Medlite And Delta Class Planetary Missions," AAS Paper 97-726, Aug. 1999.

15. Coverstone, V., Hartmann, J., Woo, B., "Outer-Planet Mission Analysis Using SolarElectric Ion Propulsion," AAS Paper 03-242, Feb. 2003.

16. Brown, C., Spacecraft Mission Design, 2nd ed., AlAA Education Series, AlAA, Reston, VA, 1998, pp. 115-117.

17. Appel, M. A., Kaplan, R. B., and Tuffias, R. H., "Liquid Fluorine/Hydrazine Rhenium Thruster Update," Marquardt Co., Van Nuys, CA, 1980, Vol. 1, pp. 85-90. 
18. Bond, D. L., "Technology Status of a Fluorine-Hydrazine Propulsion System for Planetary Spacecraft," AIAA Paper 79-0907, May 1979. 